\title{
Single Beat QTcL Interval
}

National Cancer Institute

\section{Source}

National Cancer Institute. Single Beat QTCL Interval. NCI Thesaurus. Code C123449.

The correction of the QT interval within a single beat using a linear correction formula. 